\title{
Percutaneous Endoscopic Gastrostomy Placement under NIV in Amyotrophic Lateral Sclerosis with Severe Ventilatory Dysfunction: A Safe and Effective Procedure
}

\author{
Rui Gaspar ${ }^{a}$ f Rosa Ramalho ${ }^{a, f}$ Rosa Coelho ${ }^{a, f}$ Patrícia Andrade ${ }^{a, f}$ \\ Miguel R. Goncalves ${ }^{b}, c, d, e, f \quad$ Guilherme Macedo ${ }^{a, f}$
}

\begin{abstract}
aGastroenterology Department, Centro Hospitalar São João, Faculty of Medicine of the University of Porto, Porto, Portugal; ${ }^{b}$ Noninvasive Ventilatory Support Unit, Pulmonology Department, Centro Hospitalar São João, Faculty of Medicine of the University of Porto, Porto, Portugal; ' ${ }^{\complement}$ Emergency and Intensive Care Medicine Department, Centro Hospitalar São João, Faculty of Medicine of the University of Porto, Porto, Portugal; ' ${ }^{U N N C}$ - Cardiovascular R\&D Unit, Faculty of Medicine of the University of Porto, Porto, Portugal; ${ }^{e}$ CAI_Vent - Home Mechanical Ventilation Program, Centro Hospitalar São João, Porto, Portugal; ${ }^{f}$ Faculty of Medicine, University of Porto, Porto, Portugal
\end{abstract}

\section{Keywords}

Percutaneous endoscopic gastrostomy · Amyotrophic lateral sclerosis · Severe ventilatory impairment

\begin{abstract}
Introduction: Amyotrophic lateral sclerosis (ALS) is a neurodegenerative disorder with an inexorably progressive course which leads to a progressive neuromuscular weakness. Weight loss is one of the major bad prognostic factors in ALS. The placement of percutaneous endoscopic gastrostomy (PEG) is of paramount importance in patients with dysphagia to improve the disease outcomes, although some fear exists regarding the possible ventilatory complications during the procedure. The aim of this study was to evaluate the safety and effectiveness of PEG tube insertion under non-invasive ventilation (NIV) in patients with ALS and severe ventilatory impairment. Methods: A retrospective study of all consecutive PEGs placed in our department from May 2011 to January 2018 in patients with ALS was performed. The procedure
\end{abstract}

was performed under non-invasive positive-pressure ventilation for ventilatory support. Results: We included 59 patients with ALS with severe ventilatory impairment, 58\% were female, with a mean age of $67.2 \pm 10.1$ years and a median follow-up of 6 [2-15] months. The main indication for PEG placement was dysphagia (98\%). The median time for PEG tube insertion since the established diagnosis of ALS was 12 [6-25] months and 4 [2-18] months since the beginning of bulbar symptoms. The majority of the patients had placed a 20 -Fr PEG (63\%) and under mild sedation with midazolam (80\%), all under NIV. There were no immediate complications during and after the procedure (no episodes of aspiration or orotracheal intubation) and mortality. Conclusion: The placement of PEG is a very important procedure in patients with ALS and severe ventilatory impairment. The interdisciplinary department collaboration permitted the placement of PEG under NIV, in a safe and effective procedure in this special population.

(C) 2021 Sociedade Portuguesa de Gastrenterologia Published by S. Karger AG, Basel karger@karger.com www.karger.com/pjg

Karger ${ }^{\prime \prime}$

BOPEN ACCESS
๑) 2021 Sociedade Portuguesa de Gastrenterologia Published by S. Karger AG, Basel

This is an Open Access article licensed under the Creative Commons Attribution-NonCommercial-4.0 International License (CC BY-NC) (http://www.karger.com/Services/OpenAccessLicense), applicable to the online version of the article only. Usage and distribution for commercial purposes requires written permission.
Correspondence to:

Rui Gaspar, ruilopesgaspar@gmail.com 
Colocação de gastrostomia endoscópica percutânea sob ventilação não invasiva em doentes com esclerose lateral amiotrófica com disfunção ventilatória grave: um procedimento seguro e eficaz

Palavras Chave

Gastrostomia endoscópica percutânea · Esclerose lateral amiotrófica · Disfunção ventilatória grave

\section{Resumo}

Introdução: A esclerose lateral amiotrófica (ELA) é uma doença neurodegenerativa com um curso inexorável que leva a fraqueza neuromuscular progressiva. A perda de peso é um dos principais fatores de mau prognóstico na ELA. Apesar do receio de complicações ventilatórias durante o procedimento, a colocação de gastrostomia percutânea endoscópica em doentes com disfagia é extremamente importante para melhorar o prognóstico. $\mathrm{O}$ objetivo deste estudo é avaliar a segurança e eficácia da colocação de gastrostomia percutânea endoscópica (GEP) sob ventilação não invasiva (VNI) em doentes com ELA e disfunção ventilatória grave. Métodos: Estudo retrospetivo de todas as gastrostomias percutâneas endoscópicas colocadas em doentes com ELA no nosso departamento entre Maio 2011 e Janeiro 2018. O procedimento foi realizado sob VNI para suporte ventilatório. Resultados: Foram incluídos 59 doentes com ELA e disfunção ventilatória grave, $58 \%$ do sexo feminino, com uma idade média de $67.2 \pm 10.1$ anos e um follow-up mediano de 6 [2-15] meses. A principal indicação para colocação de gastrostomia percutânea endoscópica foi disfagia (98\%). O tempo mediano para a colocação de GEP desde o diagnóstico de ELA foi 12 [6-25] meses e 4 [2-18] meses desde o início dos sintomas bulbares. A maioria dos doentes colocaram uma GEP de $20 \mathrm{Fr}$ (63\%) e sob sedação com midazolam (80\%), todos sob VNI. Não se verificaram complicações imediatas durante e após o procedimento (sem episódios de aspiração ou entubação orotraqueal) e mortalidade. Conclusão: A colocação de GEP é um procedimento muito importante em doentes com ELA e disfunção ventilatória grave. A colaboração interdisciplinar permitiu a colocação de GEP sob ventilação não invasiva, tornando-o um procedimento seguro e eficaz nesta população especial.

(c) 2021 Sociedade Portuguesa de Gastrenterologia Publicado por S. Karger AG, Basel

\section{Introduction}

Amyotrophic lateral sclerosis (ALS) is a neurodegenerative disease with progressive loss of the upper and lower motor neurons at the spinal or bulbar levels.

It is known that the course of this disorder is heterogeneous and the survival relies on several factors: clinical presentation (limb onset vs. bulbar onset), age of symptom onset, rate of disease progression, development of respiratory muscle weakness with consequent respiratory failure and nutritional status [1-4]. Since there is no therapy that offers a substantial clinical benefit for patients with ALS, it presents a very poor prognosis. Generally, death occurs due to respiratory failure, aspiration pneumonia, malnutrition, and dehydration $[1,5,6]$.

The clinical presentation of ALS is heterogeneous but typically begins with muscle weakness, twitching, and cramping in the limbs. The disease can eventually progress to bulbar involvement, presenting with dysphagia and dysarthria $[3,7]$.

Nutritional assessment is a major issue to address in patients with ALS, as it has been clearly demonstrated that weight loss is an independent poor prognostic factor. Malnutrition in ALS patients can be explained in part by poor food intake, which might be due to dysphagia, severe upper-limb disability and high ventilatory dependence in patients under continuous non-invasive positive-pressure ventilation (NIV). Dysphagia develops in the majority of ALS patients during the course of the disease and, besides being inevitably associated with weight loss and malnutrition, it also entails an increased risk of respiratory infections due to aspiration, features that are associated with a poor prognosis $[2,3,8]$.

Dietary changes are of paramount importance to preserve nutrition and can postpone the need for percutaneous endoscopic gastrostomy (PEG). However, with the progression of the disease, oral feeding will become insufficient and nutrition can only be guaranteed through PEG placement $[2,8,9]$.

Respiratory dysfunction is an established indicator of ALS severity and progression. Furthermore, vital capacity (VC) is a good indicator of respiratory function, and its decline is associated with a poor prognosis in ALS patients, especially when VC decreases to less than $50 \%$ of predicted. Thus, this parameter is most commonly used as a criterion for initiating ventilatory support. Respiratory complications are common in ALS, and NIV and, less frequently, invasive mechanical ventilation are used to alleviate symptoms of respiratory insufficiency. In fact, NIV significantly prolongs survival, preserves respiratory
Gaspar/Ramalho/Coelho/Andrade/ Goncalves/Macedo 
function and improves or maintains quality of life in ALS patients [10].

The American Academy of Neurological Societies and the European Federation of Neurological Societies guidelines for the management of ALS recommend PEG placement before the occurrence of respiratory insufficiency $(\mathrm{FVC} \leq 50 \%)$ as it reduces procedure risks and improves survival and quality of life $[10,11]$.

PEG placement is an invasive and high-risk endoscopic procedure especially in very vulnerable patients, such as ALS patients. The procedure usually requires mild sedation and is more dangerous in patients with ventilatory impairment, particularly severe respiratory impairment, and/or at an advanced stage of the disease. In this subset of patients, NIV during the PEG procedure may be feasible [10].

Our department has a dedicated team of gastroenterologists working in cooperation with the Pneumology Department that permits the insertion of a PEG tube under NIV in these high-risk patients with ALS and severe ventilatory impairment.

The aim of this study was to evaluate the PEG tube insertion under NIV in patients with ALS and severe ventilatory impairment.

\section{Methods}

\section{Study Design, Inclusion and Exclusion Criteria}

A retrospective study including all consecutive PEGs under NIV placed in the Gastroenterology Department from May 2011 to January 2018 in patients with ALS under pneumology support was performed in a tertiary centre in Porto.

All patients were actively followed at the neuromuscular outpatient clinic of the Pulmonology Department, with nutritional status and swallowing status always evaluated. Severe ventilatory dysfunction was characterized by a VC below $50 \%$ of predicted.

The criteria considered to placement of PEG were: insufficient oral feeding due to dysphagia or inability of having an entire meal without the use of NIV, weight loss $>10 \%$ and suspicion of aspiration pneumonia.

At the time of referral, all patients were evaluated by a pulmonologist and a specialized respiratory physiotherapist, as well as by the gastroenterologist in charge of patients who were candidates for PEG placement. The procedure was explained to the patient and the family, and all the periprocedure risks and implications to the future of the patient were considered. A patient or family informed consent was obtained before the procedure.

\section{Procedure}

A 12-h fasting prior to the examination was recommended to the patient and anticoagulation therapy stopped for 1 week (warfarin was substituted by enoxaparin that was stopped $24 \mathrm{~h}$ before the procedure).

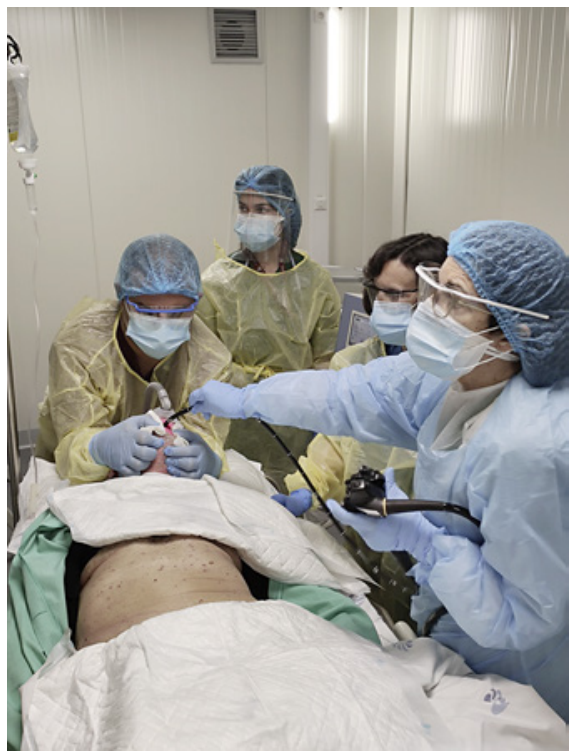

Fig. 1. Esophagogastroduodenoscopy with a standard upper endoscope for PEG placement in a patient with ALS and severe ventilatory impairment under nasal non-invasive ventilatory support.

All patients received prophylactic antibiotic treatment with $1 \mathrm{~g}$ cephazolin $1 \mathrm{~h}$ before PEG placement.

The procedure was done with an upper endoscope (Olympus ${ }^{\circledR}$ GIF-Q160, GIF-Q165 and GIF-Q180 models), and a PEG kit was used (PEG US Endoscopy ${ }^{\circledR}$ Pull Silicone (20-24 Fr).

PEG placement was performed by three operators in strict collaboration: one experienced endoscopist, one gastroenterologist responsible for the percutaneous component of the procedure and a specialized respiratory physiotherapist responsible for adjusting NIV parameters whenever it was necessary. This team was also responsible for sedation and its control (with midazolam).

An upper endoscopy was performed to exclude malignancy or gastric outlet obstruction and determine the optimal site for PEG placement. After lidocaine injection, a 2 -cm-deep horizontal incision was made and the PEG placed by the through pull method. This procedure was performed without general anaesthesia or profound sedation and under nasal NIV (Fig. 1) in spontaneous timed bilevel mode. When needed, a conscious sedation with midazolam was applied. Those patients who had not been using NIV, were adapted and trained in nasal NIV usage previously by the specialized respiratory physiotherapist to prepare them for the procedure. Estimated tidal volumes, airleaks through the mouth, $\mathrm{SpO}_{2}$, heart rate and respiratory rate were monitored continuously. Due to the increase in mouth air leaks during the PEG placement, home ventilator parameters were readjusted to achieve patient comfort. Low flow oxygen was only employed with NIV to obtain an $\mathrm{SpO}_{2}$ $\geq 92 \%$, despite NIV optimization. If $\mathrm{SpO}_{2} \geq 92 \%$ could not be reached with nasal NIV plus low flow $\mathrm{O}_{2}(\leq 2 \mathrm{~L} / \mathrm{min})$, then PEG placement was cancelled. All patients maintained NIV with their home interface for at least $3 \mathrm{~h}$ after the procedure.

\section{Data Collection}

Patient data were collected from electronic medical records. 
Age, gender, presence of dysphagia, previous episodes of aspiration pneumonias, date of established diagnosis of ALS and time of the beginning of bulbar symptoms and presence of comorbidities (diabetes mellitus, liver disease, malignancy, AIDS, moderate to severe chronic kidney disease, heart failure, previous myocardial infarction, chronic obstructive pulmonary disease, peripheral vascular disease, previous cerebral vascular accident or transitory ischaemic accident, dementia, hemiplegia, connective tissue disease and peptic ulcer disease) were obtained, and the Charlson comorbidity index was calculated.

Data regarding the procedure such as type of PEG, need of sedation and dose of midazolam and periprocedure complications were also obtained, as well as postmortality and postprocedure complications (more than 1 month after PEG tube placement).

We used our non-ALS PEG patient database to compare the rate of complications of PEG tube insertion in ALS patients.

Statistical Analysis

Continuous variables are expressed as medians (standard deviation). Categorical variables are reported as absolute (n) or relative frequencies $(\%)$.

$p$ values $<0.05$ were considered significant. Data were analysed using SPSS 21.0 (IBM Corp., Armonk, NY, USA).

\section{Ethical Considerations}

This study was conducted according to the Declaration of Helsinki.

Informed consent to participate in the study was obtained from each patient.

\section{Results}

We included 59 patients, 34 females (58\%) and 25 males $(42 \%)$, with a mean age of $67.2 \pm 10.1$ years, and the median follow-up was 6 [range 2-15] months.

The median Charlson index was 3 [2-4], and 24 patients had arterial hypertension, 13 had dyslipidaemia, 5 patients had type 2 diabetes, 3 previous episodes of cerebral vascular accident or transitory ischaemic accident and 2 previous episodes of acute myocardial infarction.

Nine patients had suspicion of previous episodes of aspiration (15.3\%), and 11 patients had previous admissions for pneumonia (10 patients 1 single episode and 1 patient with 2 admissions due to pneumonia).

The main reason for referral for PEG placement was dysphagia with associated weight loss (98.3\%).

The clinical characterization is listed in Table 1.

The median time for PEG tube insertion since the established diagnosis of ALS was 12 [6-25] months and 4 [2-18] months since the beginning of bulbar symptoms.

The majority of the patients had placed a $20-$ Fr PEG tube (62.7\%) and 47 needed midazolam sedation (92\% up to $2 \mathrm{mg}$ of midazolam). There were no immediate com-
Table 1. Clinical characterization

\begin{tabular}{ll}
\hline Clinical characterization & $n(\%)$ \\
\hline Dysphagia & $58(98.3)$ \\
Arterial hypertension & $24(40.7)$ \\
Dyslipidaemia & $13(22.0)$ \\
Type 2 diabetes & $5(8.5)$ \\
Previous cerebral vascular accident or & \\
$\quad$ transitory ischaemic accident & $3(5.1 \%)$ \\
Previous acute myocardial infarction & $2(3.4)$ \\
Heart failure & $1(1.7)$ \\
Dementia & $1(1.7)$ \\
Charlson index $\leq 3$ & $43(72.9)$ \\
Charlson index $>3$ and $<8$ & $16(27.1)$ \\
Patients with previous admission due to pneumonia & $11(18.6)$ \\
Number of previous admissions considering all causes & \\
0 & $19(32.2)$ \\
1 & $31(52.5)$ \\
2 & $4(6.8)$ \\
3 & $4(6.8)$ \\
4 & $1(1.7)$ \\
\hline
\end{tabular}

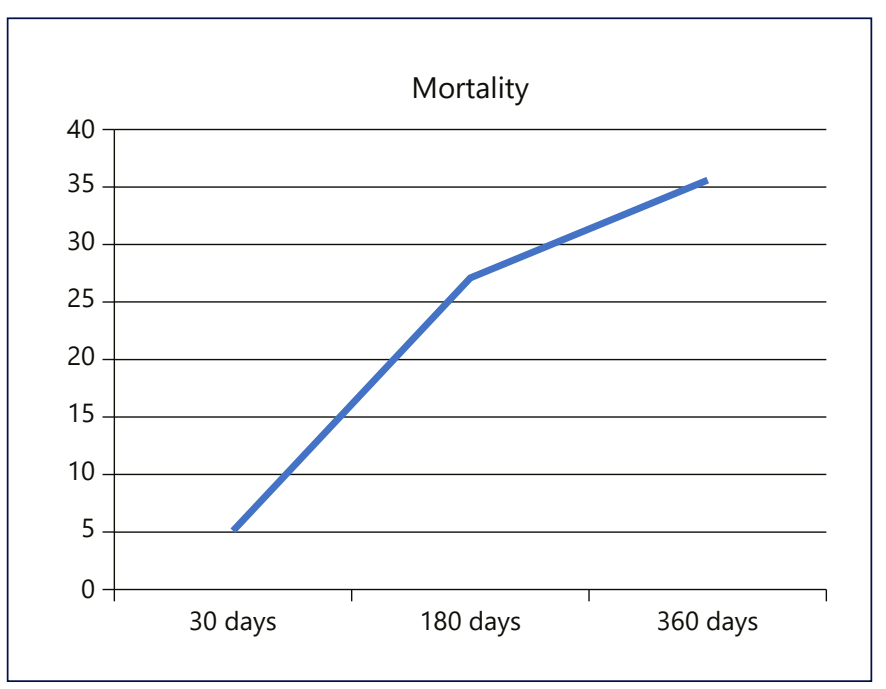

Fig. 2. 30-, 180- and 360-day mortality after PEG placement.

plications during and after the procedure (no episodes of aspiration or orotracheal intubation), need for admission or mortality. In addition, regarding minor complications, there were no episodes of apnoea/hypoventilation, aspiration pneumonia or peristomal infection in the postprocedure period.

Eleven patients developed long-term complications after PEG tube placement. Six patients needed to substitute the PEG because of 5 accidental exteriorizations and
Gaspar/Ramalho/Coelho/Andrade/ Goncalves/Macedo 
Table 2. Postprocedure complications

\begin{tabular}{lll}
\hline Long-term complications of PEG placement & $\begin{array}{l}\text { ALS patients } \\
(n=59)\end{array}$ & $\begin{array}{l}\text { Non-ALS patients } \\
(n=402)\end{array}$ \\
\hline Exteriorization & $5(8.5 \%)$ & $44(10.9 \%)$ \\
Pain & $4(6.8 \%)$ & $30(7.5 \%)$ \\
Bleeding & $1(1.7 \%)$ & $2(0.5 \%)$ \\
Degradation of PEG tube & $1(1.7 \%)$ & $29(7.2 \%)$ \\
\hline Number of admissions for all causes after PEG placement & $18(30.5 \%)$ & $128(31.8 \%)$ \\
\hline Number of admissions due to pneumonia after PEG placement & $9(15.3 \%)$ & $100(24.9 \%)$ \\
\hline
\end{tabular}

1 PEG tube degradation, 4 patients developed pain at the site of the PEG tube due to skin erythema (these cases were totally solved after topic fusidic acid use) and 1 patient had self-limited bleeding for the site of the PEG.

In the period of follow-up, there were 18 admissions after PEG placement, with 9 admissions due to pneumonia.

The 30-day mortality after PEG placement was 5.1\%, the 180 -day mortality was $27.1 \%$ and the 360 -day mortality was $35.6 \%$ (Fig. 2).

\section{Discussion}

In this study, we showed that placement of PEG under NIV in ALS patients with severe ventilatory impairment through a strict cooperation between the Gastroenterology and Pneumology Departments is a safe and effective procedure. No respiratory distress or infection, or any other pulmonary complication, was observed in this cohort of patients. No death after the procedure could be imputable to PEG placement.

Malnutrition is undoubtedly one of the main prognostic factors with some studies showing a linear decline in muscle strength. In addition, severe malnutrition is associated with muscle atrophy, muscle weakness, increase in fatigue and decrease in respiratory capacity, leading to the development of depression and decreasing quality of life $[1,8,12]$. Therefore, it is essential to provide effective nutritional care to ALS patients. Several studies have evaluated the efficacy of gastrostomies to solve this problem and linked PEG placement to decreased morbidity and improved survival rates (mainly by decreasing pneumonia and cachexia), being a successful and safe procedure in highly disabled ALS patients with respiratory compromise and advanced neurological disease $[9,13,14]$. In our opinion, it should be noted that the proposal of this pro-

Percutaneous Endoscopic Gastrostomy in Amyotrophic Lateral Sclerosis cedure should not be conditioned by the severity of the respiratory functional impairment of the patient. Otherwise, many patients would have to undergo PEG placement too early in the course of the disease and would have been unnecessarily exposed to the constraints that PEG implies. In fact, a patient with a functional and preserved deglutition and capable of autonomous breathing should not undergo PEG placement uniquely because VC is decreasing and reaching the threshold of $50 \%$ of predicted. Thus, we think that the recommendation of the American Academy of Neurology - that, for optimal management of ALS, PEG should be placed when VC is above $50 \%$ of predicted [10] - might be exaggerated and contribute to needlessly diminishing the quality of life of ALS patients. This recommendation is mainly based on the argument that it would minimize the risk of respiratory complications $[10,15,16]$. However, in a centre with an experienced and multidisciplinary team, ALS patients with severe ventilatory impairment can be addressed safely and undergo PEG placement under nasal NIV support, as we show with our results. Accordingly, an individualized approach should be undertaken to each patient, taking into account the overall condition of the patient, as well as the severity of dysphagia symptoms and the degree of malnutrition. Recently, an interesting risk-stratifying tool for the approach of PEG placement in late-stage ALS patients was proposed, considering also the NIV support during the procedure in high-risk patients [17-24].

Conscious sedation is another point of discussion in ALS patients, being carefully considered by the European guidelines, as there are only scarce data. In our study, almost $80 \%$ received conscious sedation with midazolam with simultaneous NIV and there were no changes in blood pressure, anaesthetic or respiratory complications $[3,10]$. We did not find any disadvantage of conscious sedation (in the majority of cases with $2 \mathrm{mg}$ of midazolam) compared with general anaesthesia with propofol, 
and the procedure with conscious sedation was performed without affecting technical success.

Another interesting fact is that we found fewer longterm complications of PEG placement when we compared our cohorts of PEG in our department (18.6\% in ALS patients vs. $33.8 \%$ in general patients; Table 2). This difference is even higher if we look to exteriorization and degradation of PEG. This fact might be explained because ALS patients are a population that maintain their cognitive functions preserved till very advanced phases of the disease, which will lead to careful management of the PEG tube. When we also compared the number of admissions due to pneumonia during the period of follow-up, it was also reduced even with the progressive character of the disease.

The impact of PEG on survival cannot be directly extrapolated in our group of patients, since no control group without PEG placement was enrolled. However, it is difficult to evaluate the real impact of PEG on survival, since other factors such as NIV usage, bulbar muscle impairment, timing of PEG placement and patient comorbidities might have also a significant impact on mortality. Besides that, we can assume that PEG placement is mainly a symptomatic treatment, deemed to be a quality of life measure. By reducing the risk of weight loss, malnourishment and respiratory infections due to aspiration, PEG placement might have a positive impact on the survival of ALS patients. As an additional remark, in our study population, there was a high proportion of patients under NIV. It is well known that NIV improves survival in ALS patients, a fact that was also demonstrated in our analyses, since patients under continuous non-invasive ventilatory support, despite the severity of respiratory function impairment, had a tendency for a higher median survival.

\section{Conclusion}

The placement of PEG is a very important procedure in patients with ALS and severe ventilatory impairment.

The interdisciplinary department collaboration permitted the placement of PEG under NIV, in a safe and effective procedure in this special population.

\section{Statement of Ethics}

This research was conducted ethically in accordance with the World Medical Association Declaration of Helsinki. This study protocol was reviewed and approved by the Ethics committee of Centro Hospitalar de São João. Written informed consent to participate in the study was obtained from each patient. Written informed consent was obtained from the individuals (participant and practitioners) to publish Figure 1 as well as the medical details of the case.

\section{Disclosure Statement}

The authors disclose no possible conflicts of interest.

\section{Funding Sources}

There were no funding sources to this research.

\section{Author Contributions}

Rui Gaspar was responsible for the study design, acquisition and interpretation of data, drafting the manuscript and statistical analysis. Miguel Gonçalves was responsible for acquisition and interpretation of data, and critical revision of the manuscript for important intellectual content. Rosa Ramalho, Rosa Coelho and Patrícia Andrade were responsible for acquisition and interpretation of data. Guilherme Macedo was responsible for critical revision of the manuscript for important intellectual content. All the authors approved the final version of the paper.

\section{References}

1 Cui F, Sun L, Xiong J, Li J, Zhao Y, Huang $X$. Therapeutic effects of percutaneous endoscopic gastrostomy on survival in patients with amyotrophic lateral sclerosis: a meta-analysis. PLoS One. 2018 Feb;13(2):e0192243.

2 Onesti E, Schettino I, Gori MC, Frasca V, Ceccanti M, Cambieri C, et al. Dysphagia in amyotrophic lateral sclerosis: impact on patient behavior, diet adaptation, and riluzole management. Front Neurol. 2017 Mar;8:94.
3 Strijbos D, Hofstede J, Keszthelyi D, Masclee AA, Gilissen LP. Percutaneous endoscopic gastrostomy under conscious sedation in patients with amyotrophic lateral sclerosis is safe: an observational study. Eur J Gastroenterol Hepatol. 2017 Nov;29(11):1303-8.

4 Carbo Perseguer J, Madejon Seiz A, Romero Portales M, Martinez Hernandez J, Mora Pardina JS, Garcia-Samaniego J. Percutaneous endoscopic gastrostomy in patients with amyotrophic lateral sclerosis: mortality and complications. Neurologia. 2019;34(9):582-8.
5 Brown RH Jr, Al-Chalabi A. Amyotrophic Lateral Sclerosis. N Engl J Med. 2017 Oct;377(16):1602.

6 Czaplinski A, Yen AA, Simpson EP, Appel $\mathrm{SH}$. Predictability of disease progression in amyotrophic lateral sclerosis. Muscle Nerve. 2006 Dec;34(6):702-8.

7 Zarei S, Carr K, Reiley L, Diaz K, Guerra O, Altamirano PF, et al. A comprehensive review of amyotrophic lateral sclerosis. Surg Neurol Int. 2015 Nov;6(1):171.
66

GE Port J Gastroenterol 2023;30:61-67 DOI: $10.1159 / 000519926$
Gaspar/Ramalho/Coelho/Andrade/ Goncalves/Macedo 
8 Banfi P, Volpato E, Valota C, D’Ascenzo S, Alunno CB, Lax A, et al. Use of Noninvasive Ventilation During Feeding Tube Placement. Respir Care. 2017 Nov;62(11):1474-84.

9 Spataro R, Ficano L, Piccoli F, La Bella V. Percutaneous endoscopic gastrostomy in amyotrophic lateral sclerosis: effect on survival. J Neurol Sci. 2011 May;304(1-2):44-8.

10 Andersen PM, Abrahams S, Borasio GD, de Carvalho M, Chio A, Van Damme P, et al; EFNS Task Force on Diagnosis and Management of Amyotrophic Lateral Sclerosis. EFNS guidelines on the clinical management of amyotrophic lateral sclerosis (MALS) - revised report of an EFNS task force. Eur J Neurol. 2012 Mar;19(3):360-75.

11 Miller RG, Jackson CE, Kasarskis EJ, England JD, Forshew D, Johnston W, et al.; Quality Standards Subcommittee of the American Academy of Neurology. Practice parameter update: the care of the patient with amyotrophic lateral sclerosis: multidisciplinary care, symptom management, and cognitive/behavioral impairment (an evidence-based review): report of the Quality Standards Subcommittee of the American Academy of Neurology. Neurology. 2009 Oct;73(15):1227-33.

12 Desport JC, Preux PM, Truong CT, Courat L, Vallat JM, Couratier P. Nutritional assessment and survival in ALS patients. Amyotroph Lateral Scler Other Motor Neuron Disord. 2000 Mar;1(2):91-6.
13 Shaw AS, Ampong MA, Rio A, Al-Chalabi A, Sellars ME, Ellis C, et al. Survival of patients with ALS following institution of enteral feeding is related to pre-procedure oximetry: a retrospective review of 98 patients in a single centre. Amyotroph Lateral Scler. 2006 Mar;7(1):16-21.

14 Mathus-Vliegen LM, Louwerse LS, Merkus MP, Tytgat GN, Vianney de Jong JM. Percutaneous endoscopic gastrostomy in patients with amyotrophic lateral sclerosis and impaired pulmonary function. Gastrointest Endosc. 1994 Jul-Aug;40(4):463-9.

15 Miller RG, Rosenberg JA, Gelinas DF, Mitsumoto H, Newman D, Sufit R, et al. Practice parameter: the care of the patient with amyotrophic lateral sclerosis (an evidence-based review): report of the Quality Standards Subcommittee of the American Academy of Neurology: ALS Practice Parameters Task Force. Neurology. 1999 Apr;52(7):1311-23.

16 Kasarskis EJ, Scarlata D, Hill R, Fuller C, Stambler N, Cedarbaum JM. A retrospective study of percutaneous endoscopic gastrostomy in ALS patients during the BDNF and CNTF trials. J Neurol Sci. 1999 Oct;169(12):118-25.

17 Thompson AG, Blackwell V, Marsden R, Millard E, Lawson $\mathrm{C}$, Nickol $\mathrm{AH}$, et al. A risk stratifying tool to facilitate safe late-stage percutaneous endoscopic gastrostomy in ALS. Amyotroph Lateral Scler Frontotemporal Degener. 2017 May;18(3-4):243-8.
18 Blondet A, Lebigot J, Nicolas G, Boursier J, Person B, Laccoureye L, et al. Radiologic versus endoscopic placement of percutaneous gastrostomy in amyotrophic lateral sclerosis: multivariate analysis of tolerance, efficacy, and survival. J Vasc Interv Radiol. 2010 Apr;21(4):527-33.

19 Allen JA, Chen R, Ajroud-Driss S, Sufit RL, Heller S, Siddique T, et al. Gastrostomy tube placement by endoscopy versus radiologic methods in patients with ALS: a retrospective study of complications and outcome. Amyotroph Lateral Scler Frontotemporal Degener. 2013 May;14(4):308-14.

20 Sato Y, Goshi S, Kawauchi Y, Nishigaki Y, Mizuno KI, Hashimoto S, et al. Safety of unsedated PEG placement using transoral ultrathin endoscopy in patients with amyotrophic lateral sclerosis. Nutr Neurosci. 2017 Jan;20(1):71-5.

21 ProGas Study Group. Gastrostomy in patients with amyotrophic lateral sclerosis (ProGas): a prospective cohort study. Lancet Neurol. 2015 Jul;14(7):702-9.

22 Boitano LJ, Jordan T, Benditt JO. Noninvasive ventilation allows gastrostomy tube placement in patients with advanced ALS. Neurology. 2001 Feb;56(3):413-4.

23 Sancho J, Servera E, Chiner E, Bañuls P, Gómez-Merino E, Sancho-Chust JN, et al. Noninvasive respiratory muscle aids during PEG placement in ALS patients with severe ventilatory impairment. J Neurol Sci. 2010 Oct:297(1-2):55-9.

24 Bach JR. Amyotrophic lateral sclerosis: prolongation of life by noninvasive respiratory AIDS. Chest. 2002 Jul;122(1):92-8. 